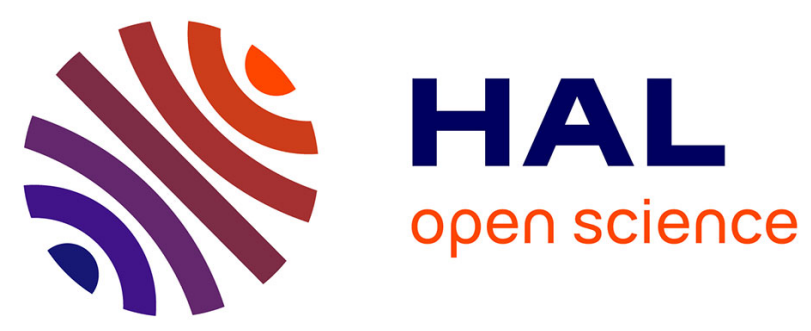

\title{
Effects of a season-long PST program on gymnastic performance and on psychological skill development
}

Claire Calmels, Jean F. Fournier, Natalie Durand-Bush, John H. Salmela

\section{To cite this version:}

Claire Calmels, Jean F. Fournier, Natalie Durand-Bush, John H. Salmela. Effects of a season-long PST program on gymnastic performance and on psychological skill development. International Journal of Sport and Exercise Psychology, 2005, 3 (1), pp.59-77. 10.1080/1612197X.2005.9671758 . hal01575583

\section{HAL Id: hal-01575583 \\ https://hal-insep.archives-ouvertes.fr/hal-01575583}

Submitted on 22 Aug 2017

HAL is a multi-disciplinary open access archive for the deposit and dissemination of scientific research documents, whether they are published or not. The documents may come from teaching and research institutions in France or abroad, or from public or private research centers.
L'archive ouverte pluridisciplinaire HAL, est destinée au dépôt et à la diffusion de documents scientifiques de niveau recherche, publiés ou non, émanant des établissements d'enseignement et de recherche français ou étrangers, des laboratoires publics ou privés. 


\title{
Effects of a Season-Long PST Program on Gymnastic Performance and on Psychological Skill Development
}

\author{
Jean F. Fournier ${ }^{1}$, Clatre Calmels ${ }^{1}$, Natalie Durand-Bush ${ }^{2}$, and John H. Salmela ${ }^{3}$ \\ 'Institut National du Sport et de l'Éducation Physique, Paris, France \\ ${ }^{2}$ University of Ottawa, Ottawa, Canada \\ ${ }^{3}$ Universidade Federal de Minas Gerais, Belo Horizonte, Brazil
}

\begin{abstract}
Findings are reported of an evaluation of the effects of a 10-month PST program on performance and psychological indicators. Ten nationally ranked female gymnasts ( $M=12$ years old) followed a psychological skills training (PST) program for half an hour per week. The five-step intervention consisted of relaxation, self-talk, goal setting, focusing, and visualization. Performance scores were obtained using scores and rankings during two consecutive competitive seasons. The OMSAT-3 ( ) was used to individually assess 11 psychological indicators (Durand-Bush, 1995). Data were recorded before the intervention and after every step of the intervention, during the course of the competitive seasons. Repeated ANOVAs as well as a practical assessment of the data were completed. The PST program appeared to be most effective on imagery skills, relaxation, activation, focusing, and refocusing. On three events out of four (bars, beam, floor), the 10 gymnasts progressed $5 \%$ more than if other gymnasts who did not follow this PST program.
\end{abstract}

Key Words: psychological skills training (PST), gymnasts, mental practice, performance, mental intervention

The effect of mental practice on performance is a theme that has received considerable attention in applied sport psychology. It has been reported that mental intervention could be a means of facilitating sport performance (Druckman \& Bjork, 1991; Vealey, 1988; Weinberg \& Comar, 1994). However, the results of the various studies have to be taken with caution by practitioners working with elite athletes; more than a decade ago, Greenspan and Feltz (1989) reported that only three of the 23 published studies of psychological interventions were carried out with elite athletes. Moreover, small to moderate improvement in the performance were observed. Papers on methodological issues of research have noted five reasons for weak effect sizes of mental skill train-

Correspondence concerning this article should be addressed to Jean Fournier, Institut National du Sport et de l'Éducation Physique, Laboratoire de Psychologie du Sport, 11, Avenue du Tremblay, 75012 Paris - France, Tel: +33141744549, E-mail: jean.fournier@insep.fr 
ing interventions (Smith, 1988; Strean \& Roberts, 1992; Tenenbaum \& Bar-Eli, 1992; Vealey, 1994): a) The use of non-athletic participants in laboratory settings, rather than elite athletes engaged in specific sport contexts; b) considerations of idiographic versus nomothetic designs; c) questionable ethical issues regarding the selection of potentially beneficial treatment applications to specific populations; d) the rarity of specific evaluation tools designed to appraise various psychological variables; and e) the short length of most interventions, which may preclude important on-going appraisal while ignoring "non-targeted performance areas" over time (Greenspan \& Feltz).

The above authors have generally suggested that a single-subject design could be a promising solution for obviating these method weaknesses. At that time, there were a total of 10 articles in the sport psychology domain which used a single-subject design (Greenspan \& Feltz, 1989). Single research design studies are becoming more common (e.g., Scott, Scott, Bedic, \& Dowd, 1999; Wanlin, Hrycaiko, Martin, \& Mahon, 1997). Basically, this research design is particularly suited for research in sport psychology intervention because it responds to the many specificities of the sport context, while avoiding the previously mentioned drawbacks of group designed studies (Hrycaiko \& Martin, 1996; Wollman, 1986; Zaichkowsky, 1980).

Furthermore, to enhance the "generalizability" of findings from single-subject design studies, multiplication of this type of research is recommended (Kazdin, 1982). Since these studies usually between one and four participants, conducting more studies will increase the general number of participants. If effects are revealed with more participants, generalizability is increased. In summary, given the nature of elite sport, the investigation of psychological factors or skills related to performance should be conducted with more elite athletes in their particular sport settings using individual assessment, sport specific multidimensional tools, and carried out over a sufficiently long period of time.

Some studies have investigated the effects of mental skill packages on performance, but no single research design study has dealt with young elite athletes. Young athletes participated in Ming and Martin's (1996) and Wanlin et al.'s (1997) single-subject designed studies. Children also participated in research involving a comparison group (Garza \& Feltz, 1998; Lee \& Hewitt, 1987; Li-Wei, Qi-Wei, Orlick, \& Zitzelsberger, 1992) but in neither case were the participants elite athletes. Only Patrick and Hryckaiko (1998) studied one elite athlete but he was over 25 years of age. Moreover, the use of multidimensional tools in the literature remains scarce. Often, only one or two mental skills were appraised, such as state anxiety and self-confidence (Savoy, 1997), team cohesion and competitive state anxiety (Cogan \& Petrie, 1995), imagery skills (Rodgers, Hall, \& Buckolz, 1991) or focusing (Bakker \& Kayser, 1994). Finally, the duration of the interventions in the single research design studies ranged from three days (Patrick \& Hryckaiko) to 12-week investigations (Shambrook \& Bull, 1996). Therefore, the authors considered that it was necessary to investigate the effects of a PST program not only utilizing many mental skills but also for a sustained period of time and with young elite athletes.

Thus, this article relates the investigation of the effects of the first year of a two-year Psychological Skill Training (PST) program on young elite gymnasts. The intervention 
consisted of five steps for teaching relaxation, self-talk, goal setting, focusing, and visualization. The composition of this package was mainly inspired by the findings in the literature.

First, relaxation is often cited as the most important skill to learn (e.g., Hardy, Jones, \& Gould, 1996; Weinberg \& Gould, 1999), mainly as a mean of releasing muscular or cognitive tension. Additionally, relaxation is deemed crucial for increasing awareness of bodily responses (Williams, 1998).

Second, goal-setting research is still expanding in the sport psychology literature. While the findings are not as consistent as in business settings, the goal-setting skill is recognized to enhance physical performance. For example, Swain and Jones (1995) demonstrated positive effects of goal setting in three out of four participants. Pierce and Burton (1998) also reported that performance-oriented gymnasts improved their performance over time. Today, goal setting is commonly presented as the way to sustain or enhance motivation in any applied sport psychology manual (e.g., Orlick, 2000; Bull, Albinson, \& Shambrook, 1996).

Third, self-talk, defined as occurring anytime one thinks about something (Bunker, Williams, \& Zinsser, 1993), is often considered as a "key to cognitive control" (Zinsser, Bunker, \& William, 1998). Self-talk is a skill whose benefits have been demonstrated on performance (e.g., Landin \& Hebert, 1999; Ming \& Martin, 1996). As such, self-talk is involved in many mental skills programs (Kendall, Hryckaiko, Martin, \& Kendall, 1990). Depending on the content of the self-talk, the performance increase can be attributed to the awareness of some cognitive function, to the countering of negative statements, to the recall of various types of goals, or even to appropriate focus on specific elements (really or in imagery) of performance.

Fourth, training and refining focusing skill is said to enhance attention (e.g., Nideffer \& Sagal, 1998). From a theoretical standpoint, the process underlying the benefits of focusing strategies and techniques is still not clear (Hardy et al., 1996). However, a recent manual on mental training in gymnastics (Cogan \& Vidmar, 2000) emphasized the need to focus on the task at hand and to ignore distraction for enhancing performance.

Finally, visualization is a popular technique among elite athletes in general (Defrancesco \& Burk, 1997), and in gymnastics in particular (Mahoney \& Avener, 1977; White \& Hardy, 1998). Moreover, the effects of imagery on performance have been demonstrated in many studies (Feltz \& Landers, 1983; Hall, 2001; Suinn, 1993). Therefore, visualization is a strong pillar of PST package intervention.

These five mental skills are basic, and as such, need to be part of PST packages for young athletes, even if an evaluation of the individual needs is also requested to supplement the mental skill education of elite athletes (Taylor, 1995). Being at the core of an introductory mental skills program, these basic techniques are particularly suited to young athletes such as gymnasts.

This article relates the investigation of the effects of the first year of a two-year Psychological Skill Training (PST) program. The design was inspired by single-subject studies. The goal of the study was twofold: a) to investigate the effects of a group PST 
program on performance, appraised in an ecologically valid situation for each gymnastic apparatus by comparing scores and rankings over two consecutive competitive seasons; and b) to investigate the effects of the program on psychological skill development across a broad variety of mental training constructs. The Ottawa Mental Skill Assessment Tool (OMSAT-3 @), Durand-Bush, 1995; Durand-Bush, Salmela, \& Green-Demers, 2001) was chosen because it allows for the appraisal of major mental skills.

The design also involves multiple baselines. It was hypothesized that each phase of the training program, if efficient, would have an effect on the corresponding mental skill and no effect on other mental skills. Because the program was taught in blocks, the length of the baselines varied for each dependant psychological variable. More specifically, six hypotheses were made: 1) the relaxation phase of the program will have an effect on the relaxation and activation subscales of the OMSAT-3@ and a potential effect on stress-reaction; 2) the goal-setting phase will influence goal-setting subscale score;

3 ) the focusing phase will have an effect on focusing and refocusing subscale scores; 4) the visualization phase will have an effect on the imagery subscale score; 5) the other subscales (self-confidence, commitment, and competition planning) representing mental skills not directly targeted will not be affected by the PST program; 6) if affected by the program, the mental-practice subscale score would vary at the introduction of the first block. No specific hypotheses were drawn regarding the self-talk phase of the program because this could have affected many variables. The originality of this research lies in the long-term investigation of young elite athletes, in the repeated measures that were conducted over 10 months, in the large number of dependent variables, and in the size of the sample of elite participants.

\section{METHOD}

\section{Participants}

Ten elite female gymnasts ranging in age from to 13 years $(M=12 \mathrm{yrs}$. old $)$ agreed to participate in the study. They all competed at the national level. Each gymnast trained four hours per day, six days per week under the supervision of four coaches. This PST program was the first exposure to psychological skill training for all 10 athletes. One of these coaches was the consultant in sport psychology who administered the program. She was preferred to an outside consultant because she was already familiar with the athletes and their discipline. Therefore the coach did play a dual role of coaching gymnastics and teaching the mental skill. Her coaching and intervention style was more democratic and humanistic than the three other coaches, unaware of sport psychology.

Although our research was of an idiographic nature, a control group was needed to account for the certain increase of performance of young developing athletes through 10 months of training. The use of control groups in PST research has been often advocated (e.g., Weinberg \& Comar, 1994). Moreover, an intervention effect in single-subject intervention is rarely attributable to a maturation process because of the short duration of these interventions. Only gymnasts of similar age (from to 13 years, $M=12$ 
yrs) and competitive category in the nation met the criteria of participating in the two consecutive competitive seasons. They formed a control group of a size similar to the experimental one. Gymnasts from this group came from four different clubs all over France. We knew that these athletes train an equivalent amount of time per week, but we cannot assure that the quality and the quantity of the training was identical to that of the experimental group. To our knowledge, the former did not take part at all in a psychological skills training program. In summary, they do not form a classical control or a placebo group, but this is as close as possible, given the ecological nature of this research. For ethical reasons, it was not possible to involve a placebo group of elite athletes. Indeed, it would have been difficult to explain to elite athletes that they were being part in an investigation for the own sake of appraising potential effect on performance. In addition, if such a group was to be used, it is very likely that gymnasts from two groups of the same training center would have talked to one another. To avoid this bias, we had to choose gymnasts out of the training center for the control group.

\section{TASK}

All participants performed their routines on the vault, bars, beam, and floor during competitions organized by the National Governing Body. These competitions included performing technical elements including $6 \mathrm{~B}$ and one $\mathrm{C}$ level difficulties, along with the other combination requirements. The evaluation was carried out during official competition by accredited judges using the International Gymnastics Federation Code of Points (1997).

\section{Experimental Design and Intervention Procedures}

Inspiration for the design came from multiple baseline single-subject studies, but the "treatment," or mental skill training program, was administered in blocks in a group situation. Since the gymnasts were young, we chose to teach them mental and organizational skills that young athletes need for their personal development, rather than selecting target behaviors for each athlete. For ethical reasons, the skills were taught to all the participants at the same time, rather than staggering the beginning of interventions over time for external validity purposes. From a methodological point of view, the lack of target behavior (for pedagogical purposes) has been bypassed by the use of a multiple baseline design. The authors hypothesized that mean scores for all the mental skills taught would increase after the establishment of baselines of different lengths. Indeed, the effect of the PST program on the mental skills would be demonstrated if each teaching block was followed by a group increase in the corresponding mental skill score. Thus, baselines for each subscale ended before the start of a new phase of the PST. For example, the baseline for relaxation was cut off just before the start of the relaxation phase, which corresponds to the fourth administration of the OMSAT-3 (C).

In addition, individual practical assessment was processed for each psychological variable of each participant, (a visual inspection of each graph), as done in single-subject design studies. This redundancy was considered to be a triangulation of method. As 
such, we consider that it was a methodological strength of our research since concurrent results were sought with two methods. Variations in dependant variables can be all the more attributed to the PST program as they are revealed by two different means of analysis.

Gymnasts completed the OMSAT-3 @ (Durand-Bush, 1995) once a week during the first month, and after each of the five phases of the mental skills training program. This lead to a total of nine administrations of the questionnaire, at weeks 1, 2, 3, 4, 15, 22, 26,32 , and 38 . After the fifth week, the test was taken in lieu of the mental skills training sessions. Performance scores were collected after each competition. Group rankings were recorded at the National Championships. In the next phase, the athletes would review the aforementioned skills and learn to plan their competitions (pre-competitive routine and plans).

\section{DePENDENT VARIABLES}

Psychological skills. The third version of the OMSAT-3 (C) (Durand-Bush, 1995; DurandBush et al., 2001) was used to collect the data. This inventory included 70 items and mental skill scales grouped under three broader conceptual components: (a) foundation skills (goal-setting, self-confidence, commitment), (b) psychosomatic skills (stress reactions, relaxation, activation), and (c) cognitive skills (imagery, mental practice, focusing, refocusing, and competition planning). The scale labeled "fear control" was not used because at the time of the study it lacked validity and was taken out of the English version for further investigation. Each item was answered on a "strongly disagree" to "strongly agree" 7-point Likert scale. Demographic items pertaining to the participants' age, sex, sport discipline, country of origin, current level of participation in sport, and highest level of education were included. The open-ended question: "Please add any comment you deem necessary" followed by half a blank page was added to the 70 questions. The original French-Canadian version of the OMSAT-3 (c) was adapted to the specificity of the French spoken in France. Moreover, certain items were reworded so that they were simple enough to be understood by young gymnasts. The French-France version of the OMSAT-3 for young athletes was first pilot tested on four gymnasts, aged 12, with one researcher present to answer possible questions. Eleven items were reworded, and this latest version was pilot tested on six additional gymnasts and considered appropriate by two researchers because the young athletes were perfectly able to understand all of the items. This version of the OMSAT-3 (c) was administered to 128 French competitive athletes in a variety of sports and age groups (12 to $18 \mathrm{yrs}$.). Measures of internal consistency estimates (Cronbach's alphas) ranged from .56 to $.83(M=.73)$. Test-retest correlations were calculated based on a second administration of the tool to 51 of the 128 athletes. For the 1 subscales, values ranged from .45 to .81 $(M=.71)$. Additional validation measures, such as a confirmatory factor analysis, are needed to establish the psychometric criteria for this version of the OMSAT-3 @) (see Durand-Bush et al., 2001). 
Performance. The performance of the gymnasts was assessed using three related measures: starting scores, final scores, and national ranking. Starting scores are the projected performance scores corresponding to given levels of difficulty within a routine. Final scores correspond to the quality of the actual performance. Starting and final scores of two competitive seasons were collected for the four events (vault, bars, beam, and floor routines) from all tournaments. Depending on the various physical condition and level of the gymnasts, scores were collected from 6 to 15 different competitive tournaments. Since only final scores are saved in the French Gymnastic federation's archives, starting scores were only available for the gymnasts of the treatment group because the coaches of these participants agreed to report it. We were not able to retrieve gymnast one's final scores from the first season because they had been lost in the archives. Gymnast 2 did not compete on the bars in the first season since she was only a substitute on the team at the time. The number of gymnast scores available in the experimental group varied from seven to ten depending on their participation in first season competitions (injured athletes, or not enrolled by their coach nor selected). Then, the percentage of progress for these average scores was calculated using the following formula: (2nd season score - 1st season score) / 1st season final score X 100. Gymnast 3 was not enrolled in the first season competitions because of her low competitive level; therefore her progress could not be computed. Finally, the mean of the percentage variations between the two seasons for the two groups were computed. The third variable consisted in the group rankings for the two seasons.

Coaches' numerical assessment of training. We asked coaches to fill out a form once a month to record their perceptions of the quality of the training. This was done by answering the same question related to the quality of training for each of their gymnasts, on each apparatus, with a 10-point Likert scale from 0 (poor training) to 10 (very good job).

\section{Treatment Conditions: Mental Skill Training Program}

The 5-step PST program consisted in 25 sessions: relaxation (8sessions), self-talk (5 sessions), goal setting ( 3 sessions), focusing ( 4 sessions) and visualization ( 5 sessions), (see Appendix). Each session lasted half an hour per week. During the season, the athletes took one 2-week and two 1-week breaks for school vacations. The first break took place between the sixth and seventh relaxation sessions, the second between the self-talk and goal setting sessions, and the third before the lastfocusing session. Each PST session was included at the end of the Thursday's training session.

\section{Procedural Reliability Assessment}

Formal procedural reliability assessment was not used. We made sure that each session was conducted according to the written description of the PST. We simply verified that all the topics had been addressed in the proper session, and that all the exercises were accomplished according to the program. 


\section{ReSUlts}

\section{RELIABILITY}

The evaluation of the gymnasts' performance was carried out during each tournament by four accredited judges using the International Gymnastics Federation Code of Points (1997). Highest and lowest scores were deleted so that scores were computed by averaging the two middle scores. This method usually ensures a reliable evaluation of performance ingymnastics.

\section{Intervention Effects on Performance}

Starting scores (level of difficulty). Four gymnasts out of nine at the vault, and seven at the asymmetrical bars improved their performance over $10 \%$ (Table 1). Group increase reached $2.8 \%$ at the beam and floor.

Table 1: Performance Variation over the Two Competitive Seasons in Starting and Final Scores

\begin{tabular}{|l|lllllllll|}
\hline & \multicolumn{2}{|c|}{ Vault (\%) } & \multicolumn{2}{c|}{ Bars (\%) } & \multicolumn{2}{c|}{ Beam (\%) } & \multicolumn{2}{c|}{ Floor (\%) } \\
\hline \multirow{2}{*}{ Gymnasts $^{\text {a }}$} & $\begin{array}{l}\text { Starting } \\
\text { scores }\end{array}$ & $\begin{array}{l}\text { Final } \\
\text { scores }\end{array}$ & $\begin{array}{l}\text { Starting } \\
\text { scores }\end{array}$ & $\begin{array}{l}\text { Final } \\
\text { scores }\end{array}$ & $\begin{array}{l}\text { Starting } \\
\text { scores }\end{array}$ & $\begin{array}{l}\text { Final } \\
\text { scores }\end{array}$ & $\begin{array}{l}\text { Starting } \\
\text { scores }\end{array}$ & $\begin{array}{l}\text { Final } \\
\text { scores }\end{array}$ \\
\hline 1 & 12.5 & $\mathrm{Na}$. & 14.3 & $\mathrm{Na}$. & 2.1 & $\mathrm{Na}$ & 4.3 & $\mathrm{Na.}$ \\
2 & 8.7 & 4.8 & 10.0 & $\mathrm{Na}$. & 6.4 & 9.4 & 2 & 13.0 \\
4 & 0 & 19.6 & 17.6 & 32.7 & 0 & 18.4 & 0 & 9.2 \\
5 & 0 & 6.2 & 16.7 & 18.9 & 2.1 & 11.0 & 2.2 & 24.8 \\
6 & 15.0 & 12.4 & 20.5 & 45.1 & 4.2 & 11.5 & 4.2 & 13.5 \\
7 & 12.5 & 7.3 & 9.1 & 9.9 & 2.0 & 8.2 & 0 & 10.5 \\
8 & 0 & -5.1 & 4.5 & -2.1 & 4.2 & 6.2 & 4.2 & 2.3 \\
9 & 2.2 & 8.3 & 16.7 & 14.2 & 2.0 & 6.7 & 4.2 & 13.7 \\
10 & 15.0 & 7.9 & 13.6 & 22.9 & 2.0 & 13.3 & 4.2 & 11.3 \\
Mean PST & 7.3 & 7.7 & 13.7 & 20.2 & 2.8 & 10.6 & 2.8 & 12.3 \\
Mean no PST & Un. & 6.8 & Un. & 15.5 & Un. & 4.2 & Un. & 7.1 \\
\hline
\end{tabular}

\footnotetext{
Na. $=$ Notapplicable, Un.$=$ Unavailable

an $=10$ forthegymnastsfrom the PST program

an $=11$ for the gymnasts outside of the program
}

Final scores (quality of execution). Six gymnasts recorded at least a $10 \%$ increase at the bars and floor, and four gymnasts increased their performance over $10 \%$ at the beam (Table 1).

National ranking. The treatment group moved from the seventh to the third place in the nation. 
Comparisons of progress. Gymnasts from the two groups increased their final scores over the course of the two seasons. Analysis of variance did not yield any significant differences between the performance scores of the two groups over the two competitive seasons. However, the progress of the 10 gymnasts participating in the PST program was five \% greater than that of the control participants for the bars, beam, and floor (Table 1).

\section{Intervention Effects on Mental Skills}

Scientific assessment of treatment effects. In single-subject design studies, two types of analyses can be conducted. Researchers can either do a graphical interpretation of the data like in Wanlin et al.'s (1997) study, or a statistical analysis. In the latter case, the binomial test is generally used to indicate whether an effect is significant. However, Shambrook and Bull (1996), for example, found that even though one of their participants had a $13 \%$ performance increase, the binomial test indicated a significant decrease $(p<.002)$. This surprising example led us to disregard this test in favor of analyses of variance.

Improvement of the psychological variables over time was analyzed using ANO$V A s$ with repeated measures on the time factor (table 2). Analyses were computed considering a repeated time factor with two modalities: 1) the baseline, and 2) the phase of the PST program. For all the dependent psychological variables, we calculated the mean scores of the subscales of the OMSAT-3 $\odot$ for each baselines and intervention phases, according to the hypotheses. Thus, baseline for relaxation and activation, stress-reaction, and mental practice subscales ended before the start of the relaxation

Table 2: OMSAT Subscales at Baseline and Intervention Phases, Along with Corresponding F-Values and Significance Levels

\begin{tabular}{|l|ll|ll|lll|}
\hline & \multicolumn{3}{|c|}{ Baseline } & \multicolumn{3}{c|}{ Intervention } & \multicolumn{3}{c|}{ ANOVA } \\
\hline OMSAT subscales & M & SD & M & SD & F-value & p & ES \\
\hline Goal setting & 5.65 & .70 & 5.84 & .75 & 1.15 & .31 & .27 \\
Self-confidence & 5.82 & .65 & 5.87 & .67 & .10 & .76 & .08 \\
Commitment & 5.90 & .66 & 5.86 & .76 & .21 & .66 & -.06 \\
Stress reaction & 3.45 & 1.15 & 3.76 & 1.22 & 1.40 & .27 & .27 \\
Relaxation & 4.12 & 1.47 & 5.44 & 1.12 & 26.45 & .0006 & .90 \\
Activation & 5.58 & 1.08 & 5.95 & .89 & 13.70 & .005 & .34 \\
Imagery & 5.09 & .88 & 6.30 & .63 & 11.58 & .008 & 1.38 \\
Mental practice & 5.47 & .81 & 5.64 & .97 & 3.61 & .09 & .21 \\
Focusing & 4.30 & 1.45 & 4.89 & 1.53 & 8.05 & .02 & .41 \\
Refocusing & 3.69 & 1.15 & 4.20 & 1.70 & 7.87 & .02 & .44 \\
Competition planning & 4.56 & 1.24 & 5.03 & 1.25 & 1.71 & .22 & .38 \\
\hline
\end{tabular}

Mean scores for the intervention phase are computed from week 5 for Self-confidence, Commitment, Stress reaction, Relaxation, Activation, Mental practice and Competition planning; from week 23 for Goal-setting; from week 27 for Focusing and Refocusing, and from week33for Imagery. 
phase, which corresponds to the fourth administration of the OMSAT-3 $\odot$. Baseline for goal-setting subscale ended before the goal setting phase (sixth administration). Baseline for focusing and refocusing subscales ended before the focusing phase (seventh administration). Baseline for imagery subscale ended before the visualization phase (eighth administration). Baseline for the remaining subscales self-confidence, commitment, and competition planning, was calculated by averaging the scores of the first four administrations, before the introduction of the first phase of the PST program.

Analyses of variance revealed a significant effect over time for relaxation, activation, imagery, focusing and refocusing, indicating improvements in group scores after each baseline (table 2). Additionally, a tendency was observed for the mental practice subscale $(p<.10)$. Means and standard deviations for all the psychological variables (baseline and intervention) are presented in table 2 along with $F$-values and significance levels.

Practical assessment of treatment effects. The individual variations over time of the mental skills were appraised through the nine measures taken with the OMSAT-3 (c). Baselines and intervention phases were identical to those used to compute the analyses of variance. We considered that the intervention had an effect when we observed a mean shift across phases or when there was less than one overlapping data point between baseline and treatment phase, or both (Kazdin, 1982). The measures of the mental skills variables were collected with 10 athletes, hereby producing 0 figures. Due to lack of space we can only summarize the results of the practical assessment, with tables

Table 3: Number of Mental Skills That Increased and Decreased per Gymnast

\begin{tabular}{|c|c|c|}
\hline Gymnasts & Increases & Decreases \\
\hline 1 & 8 & 0 \\
\hline 2 & 4 & 0 \\
\hline 3 & 5 & 3 \\
\hline 4 & 5 & 2 \\
\hline 5 & 5 & 0 \\
\hline 6 & 4 & 2 \\
\hline 7 & 8 & 1 \\
\hline 8 & 4 & 1 \\
\hline 9 & 3 & 1 \\
\hline 10 & 7 & 0 \\
\hline
\end{tabular}
$=8 / 10)$, activation $(n=6 / 10)$, focusing $(n=5 / 10)$, imagery $(n=8 / 10)$ and refocusing $(n=6 / 10)$. These findings corroborate the results from the repeated ANOVAs (Table 5).

Two athletes recorded lower goal setting, self-confidence, and reaction to stress scores, especially as competitions approached (Table 4).

Figure 1 is one example of the figures generated for gymnast 7 . For this 


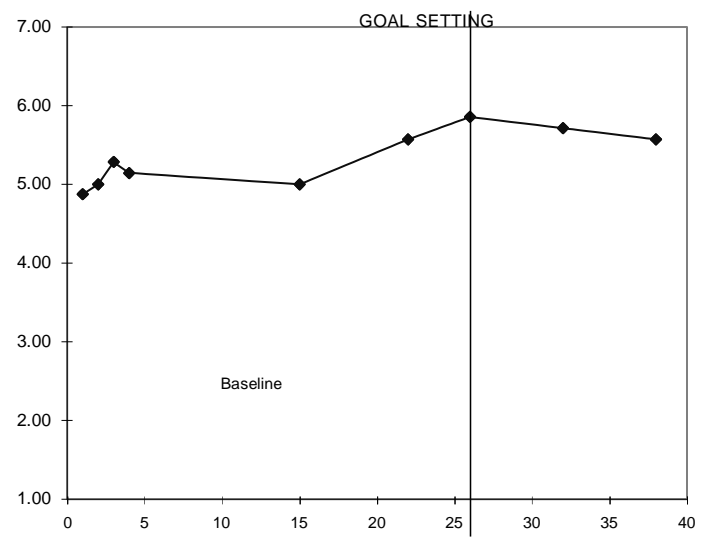

SELF-CONFIDENCE

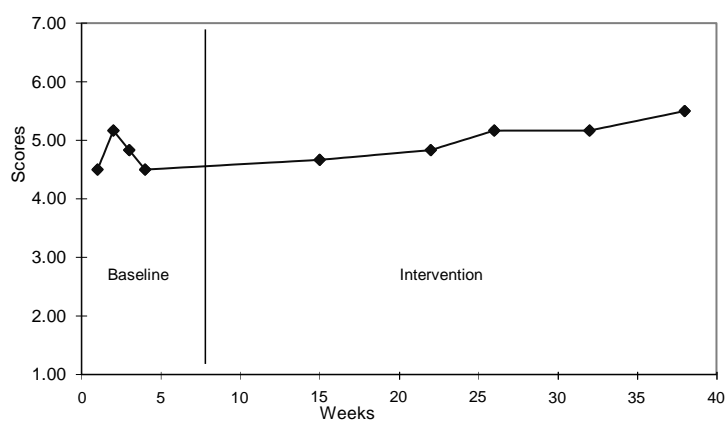

COMMITMENT

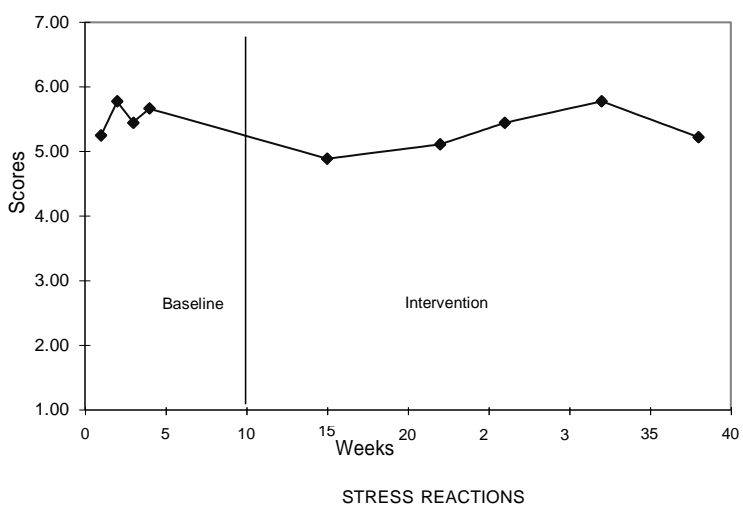

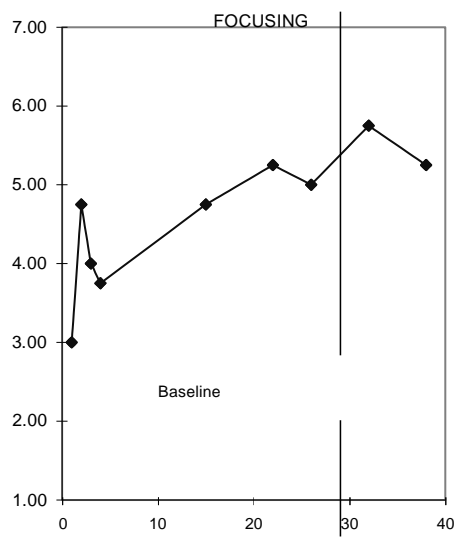

IMAGERY

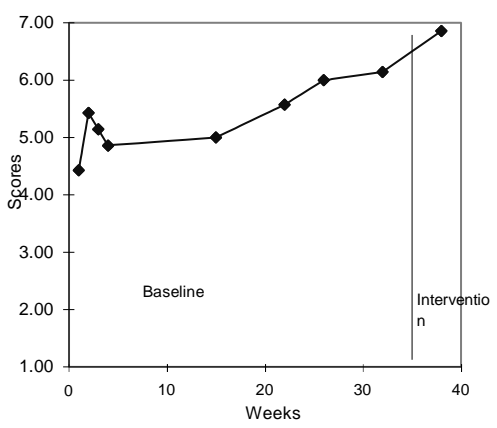

COMPETITION PLANNING

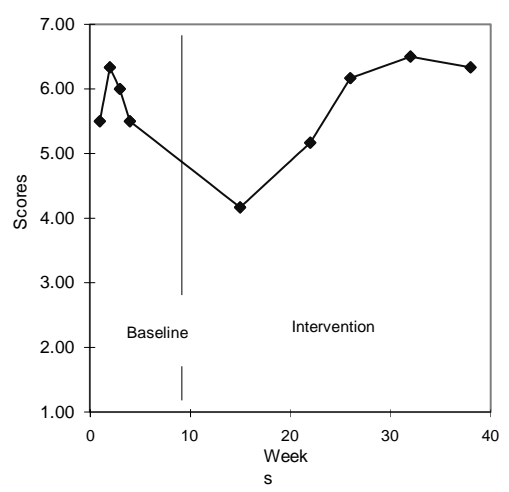

MENTAL PRACTICE

Figure 1 


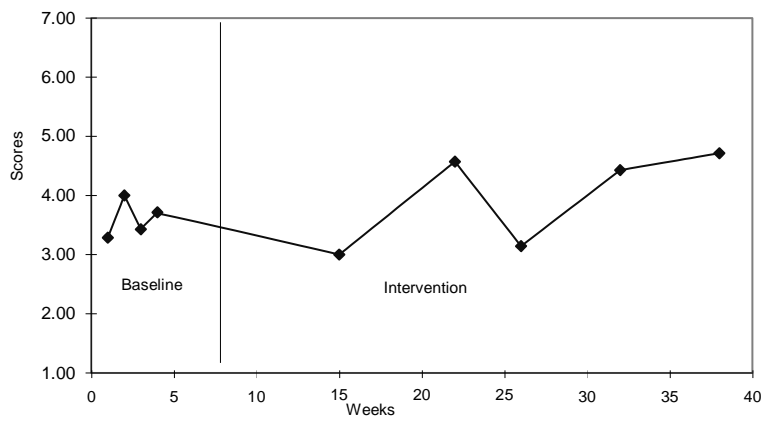

RELAXATION
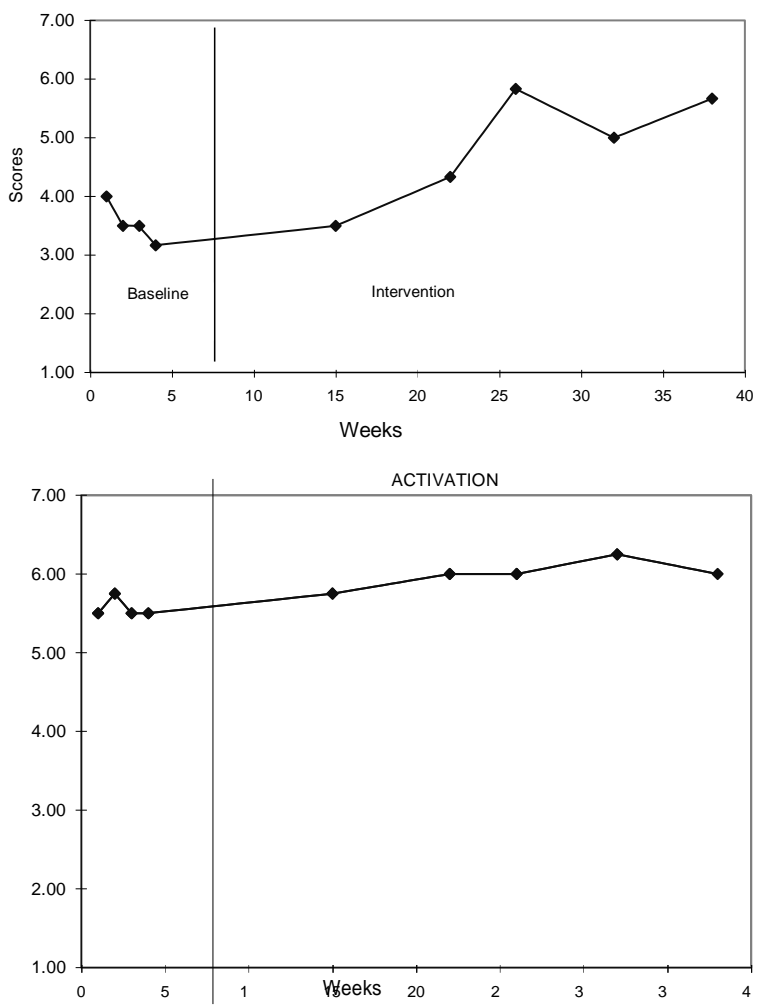

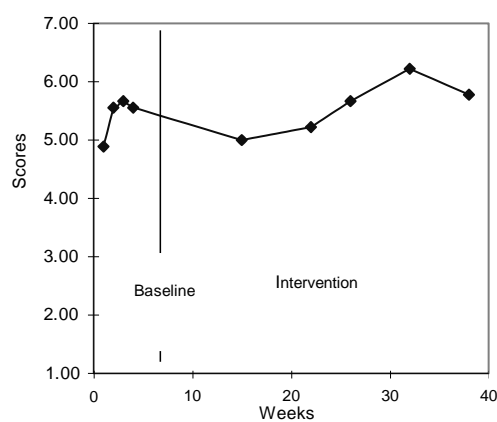

REFOCUSING

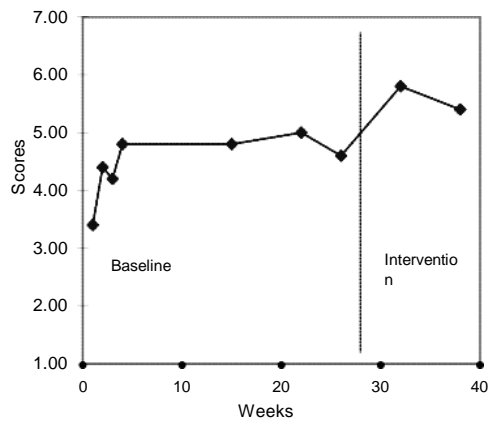

Figure 1 
Table 4: Number of Gymnasts Who Increased or Decreased Their Mental Skills

\begin{tabular}{|c|c|c|}
\hline Mental skills & $\begin{array}{c}\text { Number of gymnasts who increased } \\
\text { their mental skills }\end{array}$ & $\begin{array}{c}\text { Number of gymnasts who decreased } \\
\text { their mental skills }\end{array}$ \\
\hline Goal setting & 2 & 2 \\
\hline Self-confidence & 4 & 2 \\
\hline Commitment & 1 & 1 \\
\hline Reactionstostress & 5 & 2 \\
\hline Relaxation & 8 & 0 \\
\hline Activation & 6 & 0 \\
\hline Focusing & 5 & 1 \\
\hline Imagery & 8 & 0 \\
\hline Competition planning & 4 & 1 \\
\hline Mental practice & 4 & 0 \\
\hline Refocusing & 6 & 1 \\
\hline
\end{tabular}

participant, practical assessment indicated increases after baselines of goal setting, self-confidence, focusing, imagery, reaction to stress, relaxation, activation and refocusing. A decrease was noted for the commitment subscale. No variation after baseline was observed in mental practice and competition planning subscales. The variations detected by practical assessment were established by both indicators for all subscales but for self-confidence and reaction to stress. For the later, only a mean shift was noted after the baselines, but there was more than one overlapping data point between baseline and intervention phase.

\section{Social VALIDATION}

Social validation relates to the practical evaluation of treatment effect. In the present study, athletes gave informal feedback on the content and the style of the mental training session directly to the coach in charge of the program. This feedback mostly consisted in thanking her for taking time to conduct the sessions. This was more frequent after the relaxation sessions than the other ones. These comments are further corroborated by those regarding the help provided by the PST program in the management of training sessions and competition. For example, Gymnast 3 summarized a discussion she had with athletes 5 and 8 on "focusing." These gymnasts called focusing the cognitive behavioral routine they go through before executing a movement.

Focusing is a brief moment before each movement on an apparatus. It is also a way to think about the technical part of the movement and it is a time to recover confidence. You do that with your eyes open or closed, in whatever position you like. It is also a chance to say keywords to be more confident, or sentences for boosting your confidence. At the same time, you can use belly breathing. 
with the last, open-ended question. Here again, comments consisted in thanking the coach for giving them the opportunity to learn mental skills, such as "thank you for taking care of us." These written comments were scarce, brief, and genuine. They emphasized the pleasure of participating in the group program and occasionally, they acknowledged some potential effects in managing emotions during competition: "breathing helped me to be less scared in competition before my beam routine."

The three coaches that only coached gymnastics were questioned about what they actually appraised in training with the numerical assessment form. They gave different definitions of "training." Coach A mentioned that he appraised the progress or the acquisition of new gymnastic skills. Coach B defined training as the ability to execute properly the prescribed movements. Coach $\mathrm{C}$ distinguished quantity defined as "executing many trials at $100 \%$ commitment" from quality or the "proper execution of the movement." All three coaches specified that they raised their expectations along with the progress of the gymnasts. The ratings, therefore, remained constant so that no information could be retrieved from this monthly numerical assessment. Analysis of variance computed on these repeated evaluations did not show any differences between assessments. We do question the usefulness of this rating system. In the future, separate brief interviews, after or during the intervention program, might be a more meaningful way of evaluating the "quality of training." The coaches were more interested in the performance increases than in the PST program itself. At the end of the intervention, coaches were informed about the $5 \%$ increase in the performance of their athletes compared to the others in the nation. Coaches took pride in it and found it considerable. They attributed this difference to both the hard work and the mental training of their athletes. In summary, the program is acceptable to the athletes since: a) they thank the coach/sport psychology consultant, and b) they applied the mental skills in another context. Moreover, the consumers of the intervention (gymnasts and the 3 other coaches) are satisfied with the results obtained.

\section{Discussion}

This experimentation revealed the effects of a PST program, in an ecologically valid setting, on elite gymnasts. Performance increase was $5 \%$ greater than that of the control group for three apparatus. Group ranking increased to the point that the athletes reached the national podium. Although the difference is not statistically significant, this increase in performance corresponded to changes that were clearly noticed by the gymnasts, the coaches, and the administrators of the training center. Variations of some psychological variables targeted at the onset of the intervention were revealed by statistical analyses. Each of these people enjoyed the results, which can at least be partially attributed to the PST program.

\section{Improvement in Performance}

Starting scores: (level of difficulty). On the vault and bars, the majority of the athletes progressed mainly because their original level was low during the first season. During 
the following season, the coaches had the athletes catch up, and the latter worked hard to meet the goals set. The gymnasts were then able to perform new technical elements.

On the beam and on the floor, the level of difficulty was already high during the first season, which could explain the stagnation. The athletes directed their efforts toward the quality of the technical execution, thereby leaving the content unchanged from one season to another.

Final scores: (quality of execution). The $10 \%$ increase on the beam and on the floor for half of the gymnasts was to be expected, since the starting score is unchanged from one season to the other. Hence, the athletes targeted their efforts toward the mastery of execution.

Their progress on the bars was so noticeable that it simultaneously affected the difficulty and quality of execution. We attributed these improvements both to physical characteristics and to the quality of the basic physical training accomplished during the first season by the gymnasts.

The increase in final scores on the vault for four gymnasts could be explained in the same manner, but three gymnasts had only to enhance their execution because their starting scores were identical to the previous season.

Comparison of progress. The progress in performance of the experimental group was $5 \%$ greater than that of the control group, for the beam, bars and floor, but neither statistical nor practical differences were observable for the vault. Three explanations might account for these differences. First, the average time needed to execute the routine on the bars, beam, and floor ranged from 50 to 90 seconds. These durations are longer than those required for the vault, which is approximately five seconds. We propose that, because they improved their mental skills training, the gymnasts were better able to manage their activation level, control their attention, and cope with mistakes and distractions when the task's duration permitted. Therefore, because the vault task was of a short duration, there might not have been enough time to process correction. In this case, the second phase of the program (working on pre-competition routines) could provide additional effects. Secondly, the lack of difference in progress between the two groups for the vault could be approached from a developmental perspective in gymnastics. Indeed, in competition, athletes master the vault later than other events, possibly for morphological reasons. Young gymnasts weigh less and possess inferior muscular strength for using the springboard than older athletes, whereas the height of the vault (1.25 meters) remains constant for all age categories. Hence, for young gymnasts, there is not much room for improvement on the vault. However, these young gymnasts are able to execute more difficult figures on the vault when the springboard is replaced by a trampoline during training sessions. Thirdly, in such a methodological design were a placebo group cannot be included, the performance increase could be attributable to a Hawthorne effect. Regardless of the content of the PST program, we acknowledge that the experimenter was careful and paid attention to children in training and competitive situations where they were used to being strictly controlled. This is the major limitation of 
our study, but in such a real life intervention, we cannot offer an alternative that would be as ethical.

In summary, the effects of mental training on the performance of gymnasts were particularly noticeable for events involving tasks of comparatively greater length, whereas little improvement was recorded for the vault. The second phase of the program, which will include sessions on competition planning and the refinement of pre-competition routines, might then allow for greater improvement in their performance on the vault. This is usually the case in short duration tasks, for instance, in tennis between points (Loehr, 1994). In this regard, future research could test the hypothesis that the development of sound pre-competition routines could be more efficient for short duration tasks, while basic mental training might have more effects on longer tasks.

\section{Variations in Mental Skills}

To our knowledge, this study is the first to use a large number of psychological dependent variables, over a long period of time, for elite competitors. It is therefore difficult to analyze its results in reference to previous research. We can only enlighten our findings with studies dealing with fewer variables, or other populations. In terms of improvement of mental skills, it appears that the PST program mostly had an effect on relaxation, activation, focusing, refocusing, and imagery. Since these were skills targeted by the PST program, we consider that it was successful.

Firstly, we noticed the lack of progress in goal setting, self-confidence and commitment. These three sub-scales of the OMSAT-3@ belong to the foundation skills. At the onset of the PST program, scores were higher (in average over 5.8 out of 7) than the other sub-scales. It is likely that a ceiling effect prevented a large increase of these skills. Moreover, these basic skills might have already been mastered by these elite participants (Pierce \& Burton, 1998; Weinberg \& Weigand, 1993). This lack of progress could also be explained by the specificity of the sport. Goals of each training session were dictated exclusively by the coach, leaving little room for the setting of individual goals (Krane, Greenleaf, \& Snow, 1997; Woodman \& Hardy, 2001). The same explanation is applicable to the lack of improvement in the area of commitment. Since in elite gymnastics the workload is imposed by the coaches, it gives little opportunity for the young athletes to develop their autonomy (Ryan, 1995). Even if no effect was detected in the goal-setting subscale, we consider that it was the duty of educators to put the emphasis on various goals to counterbalance the importance of outcome goals of these elite gymnasts.

Secondly, the scores of the relaxation and activation sub-scales of the psychosomatic skills increased from the baseline to the intervention phase. This improvement was to be expected since relaxation is a keystone of PST programs (e.g., Williams, 1998). Moreover, the scores remained high even after the relaxation phase of the PST program stopped. It is likely that the gymnasts internalized the use of relaxation learned in the eight-week period (Grove, Norton, Van Raalte, \& Brewer, 1999). It seems clear that the gymnasts did learn to relax and to reinvest this skill over a long period of time. The fact that the effects of relaxation were not observable on the reaction to stress is unclear and 
requires more attention in further research. The inspection of the graphs revealed that five athletes out of ten increased their reaction to stress subscale score, while two athletes decreased their score on this same subscale. We suggest that since the relaxation sessions were more somatically oriented, any potential effects on the cognitive function were less noticeable on the Reaction to stress subscale scores.

Thirdly, the focusing, refocusing, and imagery scores of the cognitive skills also clearly notably increased during the intervention. Such an improvement in the attention skills has been found by Bakker and Kayser (1994) when teaching a PST program that involved focusing among other relaxation and imagery skills for field hockey players. The imagery score progress is also consistent with this wide domain of the sport psychology literature (e.g., Rodgers et al., 1991). We can therefore assume that the program was effective since what was taught was learned.

We have not been able to observe effects of the self-talk phase on specific mental skills such as on the self-confidence subscale, possibly because the scores were already high. However, it is also possible that the self-talk sessions were invested by the gymnasts in other mental skills as the increase of motivation, effort (Rushall, 1984) or the control of attention (Schmidt \& Peper, 1998). We must also underline that the effects of the PST program had no clear effect on mental practice for all athletes. The practical inspection of the data indicates that four athletes increased their mental practice score after the baseline. This trend for the group is corroborated by the ANOVA with a $p<.09$.

Finally, we assume that the program has been effective for producing complex pre-competitive routine for two gymnasts. It was not the purpose of this first season of psychological training to teach advanced competition planning skills and routines. However, the informal but clear oral feedback led us to understand that these gymnasts took it upon themselves to combine the mastery of their mental skills before performing. This constitutes yet another argument for hypothesizing that the skills taught during the intervention were reinvested into the practice.

One of the methodological strengths of the design of this study is that the effects of the PST program on the mental skills were detectable by different methods. Taken together, the triangulation of statistical and practical inspection of the data, along with anecdotal reports of the participants indicates clear effects of the PST program on relaxation, activation, focusing, refocusing, and imagery skills. However, since the design involves real-life situations with exceptional participants, the implications might be different from those coming from laboratory experiments. For example in this matter, the cognitive processes involved are unknown. In addition, the order of the phases has not been justified theoretically, because there is no rationale available in the literature for young elite athletes. Therefore, the order adopted was based on existing applied literature and manuals. Investigation is still needed to understand which mental skill should be taught first for the best performance enhancement.

In conclusion, this PST program targeted the improvement of mental skills and performance of young elite gymnasts. Based on the results of the study, we suggest that performance improvements are linked to or even attributable to the PST program. Replication of this type of research is needed in gymnastics and other sports to enhance the 
external validity of the results.

\section{REFERENCES}

Bakker, F. C., \& Kayser, C. S. (1994). Effect of a self-help mental training program. International Journal of Sport Psychology, 25, 158-175.

Bull, S. J., Albinson, J. G., \& Shambrook, C. J. (1996). The mental game plan: Getting psyched for sport. Eastbourne, United Kingdom: Sports Dynamics.

Bunker, L., Williams, J. M., \& Zinsser, N. (1993). Cognitive techniques for improving performance and building confidence. In J. M. Williams (Ed.), Applied sport psychology: Personal growth to peak performance (2nd ed.). Mountain View, CA: Mayfield.

Cogan, K. D., \& Petrie, T. A. (1995). Sport consultation: An evaluation of a season-long intervention with female collegiate gymnasts. The Sport Psychologist, 9, 282-296.

Cogan, K. D., \& Vidmar, P. (2000). Sport psychology library: Gymnastics. Morgantown, WV: Fitness Information Technology.

Defrancesco, C., \& Burke, K. L. (1997). Performance enhancement strategies used in a professional tennis tournament. International Journal of Sport Psychology, 18, 185-195.

Druckman, D., \& Bjork, R. A. (1991). In the mind's eye. Enhancing human performance. Washington, D.C.: National Academy Press.

Durand-Bush, N. (1995). Validity and reliability of the Ottawa Mental Skills Assessment Tool (OM$S A T-3)$. Unpublished master's thesis, University of Ottawa, Ottawa, Canada.

Durand-Bush, N., Salmela, J. H., \& Green-Demers, I. (2001). The Ottawa Mental Skills Assessment Tool (OMSAT-3*). The Sport Psychologist, 15, 1-19.

Feltz, D. L., \& Landers, D. M. (1983). The effects of mental practice on motor skill learning and performance: A meta-analysis. Journal of Sport Psychology, 5, 25-57.

Garza, D. L., \& Feltz, D. L. (1998). Effects of selected mental practice on performance, self-efficacy, and competition confidence of figure skaters. The Sport Psychologist, 12, 1-15.

Greenspan, M., \& Feltz, D. (1989). Psychological intervention with athletes in competitive situations. The Sport Psychologist, 3, 99- 2.

Grove, J. R., Norton, P. J., Van Raalte, J. L., \& Brewer, B. W. (1999). Stages of change as an outcome measure in the evaluation of mental skills training programs. The Sport Psychologist, $13,107-116$.

Hall, C. R. (2001). Imagery in sport and exercise. In R. N. Singer, H. A. Hausenblas, \& C. M. Janelle (Eds.), Handbook of sport psychology (2nd ed., pp. 529-549). New York: John Wiley \&Sons.

Hardy, L., Jones, G., \& Gould, D. (1996). Understanding psychological preparation for sport. Theory and practice of elite performers. New York: John Wiley \& Sons.

Hrycaiko, D. W., \& Martin, G. L. (1996). Applied research studies with single-subject designs: Why so few? Journal of Applied Sport Psychology, 8, 183-199.

International Gymnastics Federation Code of Points (1997). Moutier, Switzerland: Author.

Kazdin, A. E. (1982). Single-case research designs. Methods for clinical and applied settings. Oxford: Oxford University Press.

Kendall, G., Hrycaiko, D., Martin, G. L., \& Kendall, T (1990). The effects of an imagery rehearsal, relaxation, and self-talk package on basketball performance. Journal of Sport and Exercise Psychology, 12, 157-166.

Krane, V., Greenleaf, C. A., \& Snow, J. (1997). Reaching for gold and the price of glory: A motivational case study of an elite gymnast. The Sport Psychologist, it, 53-71.

Landin, D., \& Hebert, E. P. (1999). The influence of self-talk on the performance of skilled female tennis players. Journal of Applied Sport Psychology, it, 263-282.

Lee, A. B., \& Hewitt, J. (1987). Using visual imagery in a flotation tank to improve gymnastic performance and reduce physical symptoms. International Journal of Sport Psychology, 18, 223-230.

Li-Wei, Z., Qi-Wei, M., Orlick, T., \& Zitzelsberger, L. (1992). The effect of mental imagery training 
on performance enhancement with 7-10 year-old children. The Sport Psychologist, 6, 230241.

Loehr, J. E. (1994). The development of a cognitive-behavioral between-point intervention strategy for tennis. In S. Serpa, J. Alves, \& V. Pataco (Eds.), International perspectives on sport \& exercise psychology (pp. 219-233). Morgantown: Fitness Information Technology.

Mahoney, M. J., \& Avener, M. (1977). Psychology of the elite athlete: An exploratory study. Cognitive Therapy and Research, 1, 135-141.

Ming, S., \& Martin, G. L. (1996). Single-subject evaluation of self-package for improving figure skating performance. The Sport Psychologist, 10, 227-238.

Nideffer, R. M., \& Sagal, M. (1998). Concentration and attention control. In J. M. Williams (Ed.), Applied sport psychology: Personal growth to peak performance (pp. 296-315). Mountain View, CA: Mayfield.

Orlick, T. (2000). In pursuit of excellence: How to win in sport and life through mental training. Champaign, IL: Human Kinetics.

Patrick, T. D., \& Hryckaiko, D. (1998). Effects of a training package on an endurance performance. The Sport Psychologist, 12, 283-299.

Pierce, B. E., \& Burton, D. (1998). Scoring the perfect 10: Investigation the impact of goal-setting styles on a goal-setting program for female gymnasts. The Sport Psychologist, 12, 156-168.

Rodgers, W., Hall, G., \& Buckolz, E. (1991). The effect of an imagery training program on imagery ability, imagery use, and figure skating performance. Journal of Applied Sport Psychology, 3, 109-125.

Rushall, B. S. (1984). The content of competition thinking. In W. F. Straub \& J. M. Williams (Eds.), Cognitive sport psychology (pp.51-62). Lansing, New-York: Sport Science Associates.

Ryan, J. (1995). Little girls in pretty boxes: The making and breaking of elite gymnasts and figure skaters. New York: Doubleday.

Savoy, C. (1997). Two individualized mental training programs for a team sport. International Journal of Sport Psychology, 28, 259-270.

Schmid, A. B., \& Peper, E. (1998). Strategies for training concentration. In J.M. Williams (Ed.), Applied sport psychology: Personal growth to peak performance (pp. 316-328 ). Moutain View, 